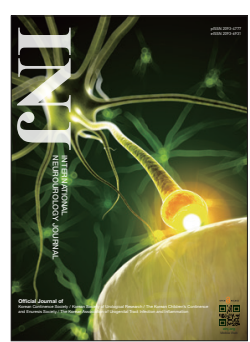

\title{
Time for a New Start for the International Neurourology Journal
}

\author{
Tack Lee (iD https://orcid.org/0000-0001-8508-9099 \\ Department of Urology, Inha University Hospital, Incheon, Korea \\ E-mail: lee.tack33@gmail.com
}

Almost 10 years have passed since I took over the responsibility of serving as the editor-in-chief of the International Neurourology Journal (INJ). It has been a wonderful experience and an unparalleled opportunity to grow both personally and professionally.

I believe that, via journals, researchers all over the world share their peer-reviewed results, thereby stimulating new ideas and innovations by new researchers. This means that most new ideas are based on a synthesis of the old ideas of previous researchers. Thus, research misconduct embedded in those old ideas can mislead new researchers, causing those who try to build on previously reported results to waste enormous amounts of time, effort, and resources. Throughout my years as editor-in-chief, I was committed to making ethical issues a top priority. In this context, I am honored to state that the present editor-in-chief of INJ, Dr. Hong-Sang Moon, is the most ethical person I personally know. I expect that our journal will be continue to be run under this principle by Professor Moon.

All new ideas derive from old ideas, but not all combinations of old ideas contribute equally to new ideas. Basic research, also referred to as fundamental science, improves our understanding of clinical problems and ability to predict their course; therefore, clinical innovations should be fueled by basic research. In other words, clinical practice is always built on a solid foundation of basic research. Thus, our journal aims to disseminate the knowledge and discoveries gained from basic science, as well as clinical research, and our new editor-in-chief will take the lead in these initiatives.

It is quite difficult to list everyone who has helped me over the last 10 years, but I would like to express my utmost gratitude to my fellow members of the editorial board (Professor Hong Sang Moon, Professor Khae Hawn Kim, Professor Young Sam Cho, Professor Su Jin Kim, Professor Jin Wook Kim), our superb manuscript editor (Mr. Hwan Tae Ahn) and my international colleagues (Professor Karl-Erik Andersson, Professor Lori Birder, Professor Ja-Young Kim) for their unwavering support. I will return to the status of a general researcher and try to help a little with the development of neurourology. In the meantime, I would like to express my deepest thanks for this experience.

- Conflict of Interest: No potential conflict of interest relevant to this article was reported. 